\title{
Antioxidant Protection against Pathological Mycotoxins Alterations on Proximal Tubules in Rat Kidney
}

\author{
Awatef Ali ${ }^{1}$ and Susan Abdu ${ }^{2}$ \\ ${ }^{1}$ Zoology Department, Faculty of Science, Alexandria University, Egypt \\ ${ }^{2}$ Biology Department, College of Girl’s Science, King Abdulaziz University, Saudi Arabia \\ Corresponding author: Awatef Ali, PhD, Associate Professor, Zoology Department, Faculty \\ of Science, Alexandria University, Egypt
}

Submission date: March 1, 2011; Acceptance date: April 14, 2011; Publication date: April 15, 2011

\begin{abstract}
:
Background: Ochratoxin A (OTA) was one of the mycotoxins and received attention worldwide because of the hazard it posed to human and animal health, where the kidney was the primary target organ for OTA toxicity. In the other hand, dates served as a good source of natural antioxidants and could potentially be considered as a functional food.
\end{abstract}

Methods: The study was performed in the department of biology in King Abdulaziz University. Animals were gavage administrated and divided into four groups: first group received (sodium bicarbonate), second group received (289 $\mu$ g OTA $/ \mathrm{kg} \mathrm{B.W.} \mathrm{/day),} \mathrm{third}$ group received (1mg Ajwa/kg B.W. / day) and fourth group received (289 $\mu \mathrm{g}$ OTA $/ \mathrm{kg}$ B.W./day+ 1mg Ajwa /kg B.W. / day). Serum (creatinine - urea) levels were measured in each group at the time of tissue collection, some biopsies were fixed in $10 \%$ buffered formalin solution for light microscopy processing stained with Haematoxylin and Eosin (H\& E.), Periodic Acid-Schiff (PAS) and Masson's Trichrome (M.T.).Other biopsies were immediately collected into electron microscopy processing.

Results: After 28 days, a significant decrease in body weight, kidney weight and relative weight was detected in OTA treated group. Also, Serum (creatinine - urea) level were elevated .The normal cyto-architecture of proximal tubules were lost exhibiting damaged bruch border, degenerated, binucleated and karyomegalic cells. The most destructed ultrastructure was the mitochondria which severely swollen with disintegrated membranes. In Ajwa Date extract-group the proximal tubules were normal, whereas in Ajwa date extract + OTA -group the severity of the lesions was significantly reduced. 
Conclusion: The present results indicated that, Ajwa date have protective effects and ameliorated the lesions of Ochratoxin nepherotoxicity which might lead to kidney failure.

Key words: Ochratoxin A., Ajwa date, proximal tubules, light -structure, ultra -structure, biochemical analysis, morphometry.

\section{Background}

Ochratoxin (A) (OTA) was one of the mycotoxins and receiving attention worldwide because of the hazard it posed to human and animal health where the kidney was the primary target organ for OTA toxicity. Contamination of cereals and grains with Aspergillus and Penicillium fungi had resulted in the production of the mycotoxin OTA. This contamination with OTA had been associated with the induction of Balkan nephropathy in humans and porcine nephropathy in domestic swine, as well as carcinogenesis [1] where OTA was a potent renal carcinogen [2] and carcinoma arised from male rat renal parenchyma was an aspect of the nephrotoxicity of OTA and was a factor in considering application of animal data to human health risk assessment [3].

\section{Introduction}

Ochratoxin (A) was a secondary metabolite, produced by Aspergillus ochraceus (A. alutaceus) [4]. After consumption of contaminated food, OTA had been identified in blood, bile, and urine of humans and animals [5]. Numerous animal studies, showed development of renal disease due to OTA oxidative stress [6] accompanied by proximal tubular atrophy and cortical interstitial fibrosis after exposition to OTA [7] as kidney was the primary target organ for OTA [8].

Nutritional science has been expanding the knowledge of how foods influence consumers in relation to specific health parameters, where high fruit and vegetable consumption was associated with a reduced risk of several chronic diseases such as cancer, cardiovascular disease, neurodegenerative disease and inflammation [9]. The compounds thought to be responsible for the protective effects of a fruit and vegetable-rich diet include carotenoids and antioxidant vitamins; in this regard, attention has been focused on the significance of phenolics such as phenolic acids, flavonoids, and in particular anthocyanins [10].

All Date varieties served as a good source of natural antioxidants and could potentially be considered as a functional food or functional food ingredient [11], where Date fruit extract had strong antioxidant and antimutagenic properties [12]. Dates at the rutab and tamar maturity and ripening stages contained a wide array of phenolic antioxidants [13] where they possess antioxidative properties in vitro [14]. Saafi et al. [15] indicated that in vivo date palm fruit might be useful for the prevention of oxidative stress induced hepatotoxicity. Selenium, believed to help in preventing cancer and important in immune function, was also found in Dates. Also, Dates contain 23 types of amino acids and at least 
six vitamins, including a small amount of vitamin $C$ and vitamins B (1) thiamine, B (2) riboflavin, nicotinic acid (niacin), and vitamin A.[16].

Since OTA was nephrotoxic, simultaneous occurrence as food contaminants might lead to severe renal damage; there was scarce information on sub-cellular changes and there was no study converting the direct nutritional and functional properties of Dates. The present investigation was undertaken to assess the proximal tubules alterations in male rats fed OTA and to investigate detailed information about Ajwa Dates which could lead to a better understanding of their use as functional foods and ingredients in nutraceuticals, pharmaceuticals, and medicine against pathological effects caused by OTA.

\section{Material and Methods:}

\section{Materials:}

OTA: Ochratoxin A (Cat. No. 01877) were purchased from Sigma-Aldrich chemical company (U.S.A). It was dissolved in 0.5 M HNaCO3 PH 7.4.

\section{Preparation of Date Fruit Extract:}

Fruit flesh was extracted according to Miller et al. [17]:

The date fruits were manually separated from the pits, the water extract of the date fruit was made by adding distilled water to coarsely pounded date fruit (3:1) and leaving for $48 \mathrm{~h}$ in a refrigerator $\left(4^{\circ} \mathrm{C}\right)$ with continuous stirring. The aqueous extract was then used daily for 28 consecutive days.

The use of equivalent dates dose to rats was the daily amount of the human person, which was estimated according to the seven fruits of the interview, said the Prophet: "He who eats seven dates every morning will not be affected by poison or magic on the day he eats them" cited by Change et al. [18].

\section{Experimental Animals:}

The study was conducted at King Abdulaziz University Jeddah, Saudi Arabia from 20082010. Twenty eight weaning male albino Wistar rats (Rutus narvegigus) weighing $40 \pm 5 \mathrm{~g}$. was obtained from the Experimental Animal House Center, King Abdulaziz University Jeddah, Saudi Arabia. All animals were given food (rat chow), water ad libitum, were maintained at a relative humidity of $65 \%$ to $86 \%$, and a temperature of $18-20^{\circ} \mathrm{C}$. The use of animals was approved by the ethical requirements of the Animals Research Ethic Committee of KAU.

\section{Methods:}

The animals were distributed equally into four groups and were treated for four weeks (5 days/week) by gavage: First group: control animals received sodium bicarbonate buffer: 0.1 M, pH 7.4. Second group: animal's received $289 \mu \mathrm{g}$ OTA /kg B.W. / day). Third group: animals received $1 \mathrm{mg}$ Ajwa dates $/ \mathrm{kg}$ B.W. / day). Fourth group: animals received $1 \mathrm{mg}$ 
Ajwa dates $+289 \mu \mathrm{g}$ OTA $/ \mathrm{kg} \mathrm{B.W.} \mathrm{/} \mathrm{day).}$

Serum (creatinine-urea) levels were measured in each group at the time of tissue collection as blood was collected in heparinized tubes from optical vein. Plasma samples were separated by centrifugation and were measured by radio immunoassay (RIA) according to the methods of [19].

The animals were weighted then autopsied and the left kidneys were removed weighed and relative weights were calculated. Some biopsies were fixed in $10 \%$ buffered formalin solution for light microscopy processing stained with H\&E, Periodic Acid-Schiff and Masson's Trichrome stains [19]. Five micrometer paraffin sections were stained with $H \& E$ for morphometry. Twenty tubules from each group were chosen randomly $($ at $40 \times)$ in the cortex of section were evaluated. The area of proximal tubules, proximal lumen, and proximal nuclei were measured under a light microscope (Olympus $\mathrm{Cx}$ 31) using a micrometric ocular. Other biopsies were immediately collected into electron microscopy processing.

\section{Statistical analysis:}

Body and kidney weight, tubular and nuclei area, creatinine, and urea levels were analyzed by using the program SPSS version 15 where One way Anova [20] was used to assess the significance of changes between control and treated mice. The data were expressed as: Mean \pm Stander Error $(\mathrm{M} \pm \mathrm{SE})$.

\section{Results:}

\section{a- Change in body and kidney weights:}

Regarding general toxicity parameters, in this study, insignificant reduction in both body and kidney weight in the low dose OTA- group were recorded; this led to low relative weight i.e. the OTA- group recorded the minimum value for body weight $(163.28 \pm 2.71 \mathrm{~g}$.), kidney weight $(0.03 \pm 0.02 \mathrm{~g}$.), and relative weight $(0.26 \pm 0.01)$ where the control group recorded the maximum value for body weight $(173.45 \pm 1.10$ g. $)$, kidney weight $(0.51 \pm 0.03$ g.), and relative weight $(0.30 \pm 0.01)$. On the other hand, body and kidney weight had a significant decrease in Ajwa date + OTA -group and a significant increase in Ajwa Date- group in compare with control-group (Table 1).

Table 1. Statistical analysis of body, kidney and relative weight of experimental groups

\begin{tabular}{llcccc}
\hline \multicolumn{1}{c}{ Experimental } & groups & $\begin{array}{c}\text { Control } \\
\text { group }\end{array}$ & $\begin{array}{c}\text { OTA } \\
\text { group }\end{array}$ & $\begin{array}{c}\text { Ajwa date } \\
\text { group }\end{array}$ & $\begin{array}{c}\text { Ajwa date +OTA } \\
\text { group }\end{array}$ \\
\hline $\begin{array}{l}\text { Body weight } \\
\text { at zero day (g.) }\end{array}$ & mean \pm S.E & $35.93 \pm 1.37$ & $36.58 \pm 1.22$ & $35.88 \pm 1.27$ & $35.95 \pm 0.79$ \\
$\begin{array}{l}\text { Body weight } \\
\text { at fourth week (g.) } \\
\text { kidney weight (g.) }\end{array}$ & mean \pm S.E & $173.45 \pm 1.10$ & $163.28^{*} \pm 2.71$ & $172.10 \pm 2.03$ & $165.48^{*} \pm 3.64$ \\
Relative weight (\%) & mean \pm S.E & $0.51 \pm 0.03$ & $0.03 \pm 0.02$ & $0.50 \pm 0.30$ & $0.39^{*} \pm 0.01$ \\
& & $0.30 \pm 0.01$ & $0.26^{*} \pm 0.01$ & $0.30 \pm 0.02$ & $0.25^{*} \pm 0.01$ \\
\hline
\end{tabular}

\footnotetext{
* Significantly different from the control, $\mathrm{P}<0.05$
} 


\section{b-Biochemical analysis:}

With respect to biochemical parameters, creatinine reached the maximum value $(35.43 \pm$ $0.43 \mathrm{mmol} / \mathrm{L})$ in OTA- group and the minimum value in Ajwa date-group (29.71 \pm $1.46 \mathrm{mmol} / \mathrm{L}$ ) i.e. non significant decrease in creatinine level. In the Ajwa date-group non significant increase in urea level were recorded in compare with control-group i.e. maximum value obtained by Ajwa date-group $(6.07 \pm 0.04 \mu \mathrm{mol} / \mathrm{L})$ and minimum value obtained by Ajwa date + OTA -group $(5.57 \pm 0.33 \mu \mathrm{mol} / \mathrm{L})$. Also, in this study the positive effect of Date appeared where low level of both creatinine and urea were recorded in Ajwa Date + OTAgroup in compare with OTA- group (Table 2).

Table 2. Statistical analysis of serum creatinine, and urea concentration in experimental groups

\begin{tabular}{lccccc}
\hline Experimental groups & $\begin{array}{c}\text { Control } \\
\text { group }\end{array}$ & $\begin{array}{c}\text { OTA } \\
\text { group }\end{array}$ & $\begin{array}{c}\text { Ajwa date } \\
\text { group }\end{array}$ & $\begin{array}{c}\text { Ajwa date } \\
\text { +OTA group }\end{array}$ \\
\hline Creatinine $\boldsymbol{\mu m o l} / \mathrm{L}$ & mean \pm S.E & $43.33 \pm 1.02$ & $35.43 \pm 0.43$ & $29.71 \pm 1.46$ & $33.57 \pm 1.84$ \\
Urea $\mathbf{m m o l} / \mathrm{L}$ & mean \pm S.E & $5.74 \pm 0.16$ & $5.83 \pm 0.25$ & $6.07 \pm 0.04$ & $5.57 \pm 0.33$ \\
\hline
\end{tabular}

* Significantly different from the control, $\mathrm{P}<0.05$

\section{c- Morphometric results:}

The proximal tubule appeared to be major site of renal injury and this was illustrated in table

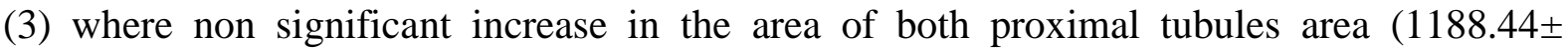
$\left.28.84 \mu \mathrm{m}^{2}\right)$, proximal tubules lumen $\left(139.88 \pm 10.00 \mu \mathrm{m}^{2}\right)$, and proximal tubules nuclei $\left(42.44 \pm 3.48 \mu \mathrm{m}^{2}\right)$, were detected in OTA- group which recorded the maximum values. Non

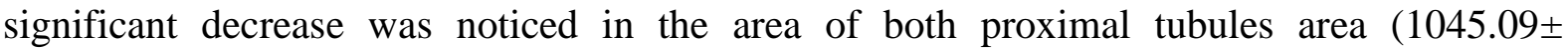
$\left.34.21 \mu \mathrm{m}^{2}\right)$, proximal tubules lumen $\left(99.08 \pm 6.07 \mu \mathrm{m}^{2}\right)$ in OTA+ date-group which detected the minimum value while the control group showed the minimum value for proximal tubules nuclei $\left(26.94 \pm 0.5 \mu \mathrm{m}^{2}\right)$.

Table 3. Histological measurements of proximal tubules

\begin{tabular}{|c|c|c|c|c|c|}
\hline \multicolumn{2}{|c|}{ Experimental groups } & \multirow[t]{2}{*}{ Control group } & \multirow{2}{*}{$\begin{array}{c}\text { OTA } \\
\text { group }\end{array}$} & \multirow{2}{*}{$\begin{array}{l}\text { Ajwa date } \\
\text { group }\end{array}$} & \multirow{2}{*}{$\begin{array}{c}\text { Ajwa date } \\
+ \text { OTA group }\end{array}$} \\
\hline Variable & & & & & \\
\hline $\begin{array}{l}\text { Area of proximal } \\
\text { tubules }\left(\mu^{2}\right)\end{array}$ & mean \pm S.E & $1090.95 \pm 56.31$ & $1188.44 \pm 28.84$ & $1098.33 \pm 48.92$ & $1045.09 \pm 34.21$ \\
\hline $\begin{array}{l}\text { Area of proximal } \\
\text { tubules lumen } \\
\left({\left.\mu \mathrm{m}^{2}\right)}^{2}\right.\end{array}$ & mean \pm S.E & $104.78 \pm 5.75$ & $139.88 * \pm 10.00$ & $107.91 \pm 9.18$ & $99.08 \pm 6.07$ \\
\hline $\begin{array}{l}\text { Nuclei area } \\
\text { ofproximal tubule } \\
\left(\mu \mathrm{m}^{2}\right)\end{array}$ & mean \pm S.E & $26.94 \pm 0.51$ & $42.44^{*} \pm 3.48$ & $29.74 \pm 0.61$ & $34.57 * \pm 3.08$ \\
\hline
\end{tabular}

* Significantly different from the control, $\mathrm{P}<0.05$ 


\section{d-Light and TEM observations:}

Plate (1):
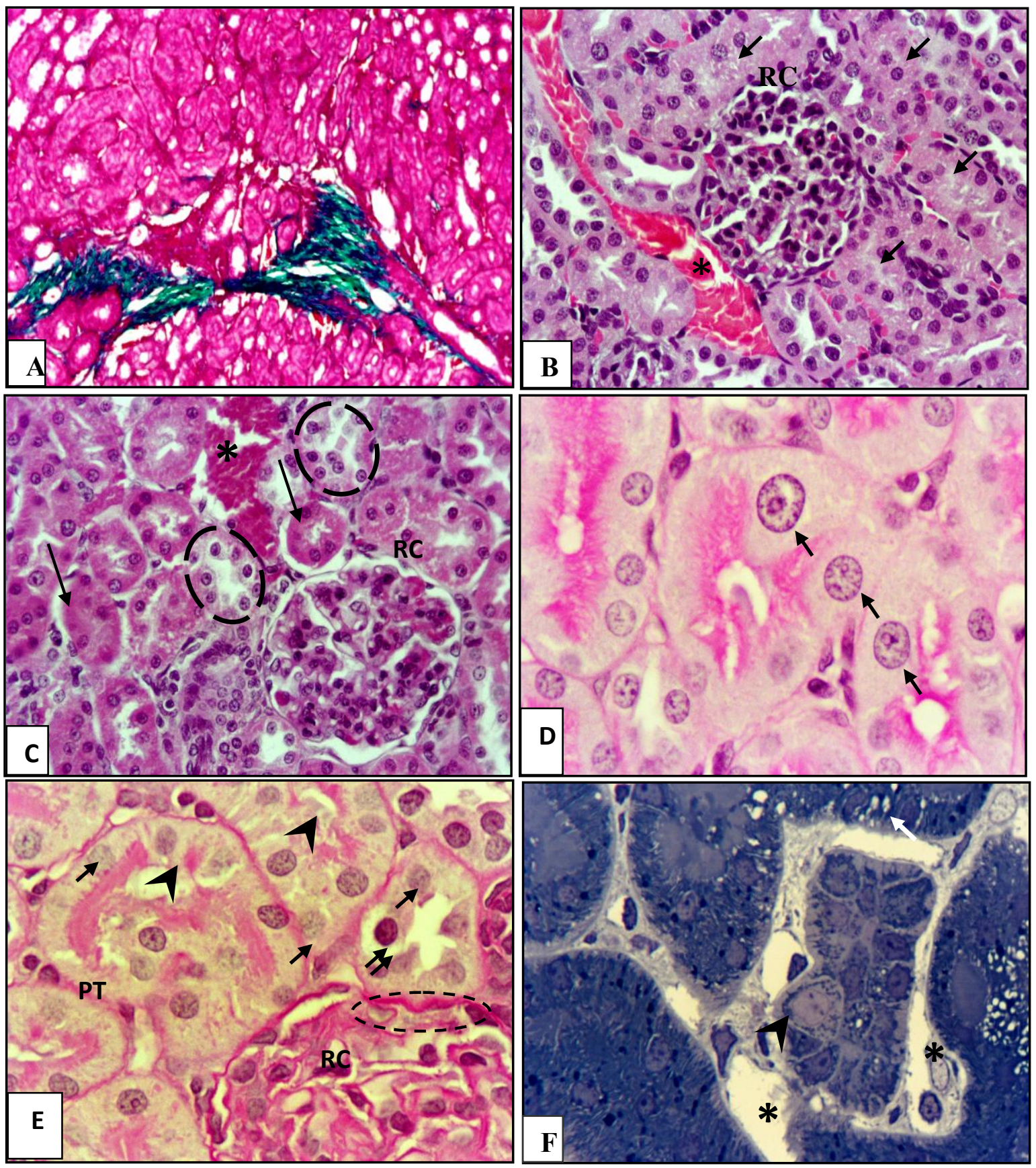

Plate 1: Light photograph for transverse section of OTA- group kidney showing:

A-Fibrosis in interstitial tissue (M.T.x100). B-Renal corpuscle (RC) with obliteration of both capillaries and urinary space, sever mesangial cell proliferation and visceral layer adherence to Bowman's capsule. Note eosinophilic casts within proximal tubules lumen (arrows) and stasis of $\mathrm{RBC}_{\mathrm{s}}$ in interstitium (*) (H. \& E.; X400). C-Renal corpuscle (RC) with focal segmental glomerulus and undifferentiating capillaries lumen. Atrophied proximal tubules 
which separated from basement membrane \& deformed and stained intensely (arrows), degenerative distal convoluted tubules with lytic cytoplasm (black detached line) and congestion in interstitial tissue (*) (H. \& E.; X400). D-Proximal tubules with megacytosis of tubular cell containing enlarged nuclei (karyomegaly) (arrows) (P.A.S.; X1000). E-Renal corpuscle (RC) with unclear urinary space due to proliferation of podocyte (detached line), proximal tubules (PT) revealing brush border loss (head arrows), nuclear condensation (double arrow) and karyolysis (arrows) (P.A.S.; X1000). F-Large number of lysosome-like vesicles and vacuoles (arrows) well demonstrated in proximal tubules and relatively expanded capillaries in interstitial tissue (*). Note megacytosis of tubular cell containing enlarged nuclei (karyomegaly) (head arrows) (T.B.; X1000).

Serious damage to kidney occurred by the nephrotoxic actions of OTA which led to necrosis of renal tubular cells. The present results showed marked interstitial fibrosis (Plate 1A), cloudy swelling of proximal tubules in addition to tubular eosinohilic intraluminal proteinaceous casts (Plate 1B.), atrophied dense tubules separated from basement membrane and congestion in interstitial tissue (Plate 1C). Also, karyomegalic nuclei in tubular epithelial cells were observed (Plate $1 \mathrm{D}$ ). In addition to these findings focal loss of brush border and karyolysis (Plate.1E) as a result of megacytosis the tubules appeared with no lumen (Plate 1 F).

Plate (2):

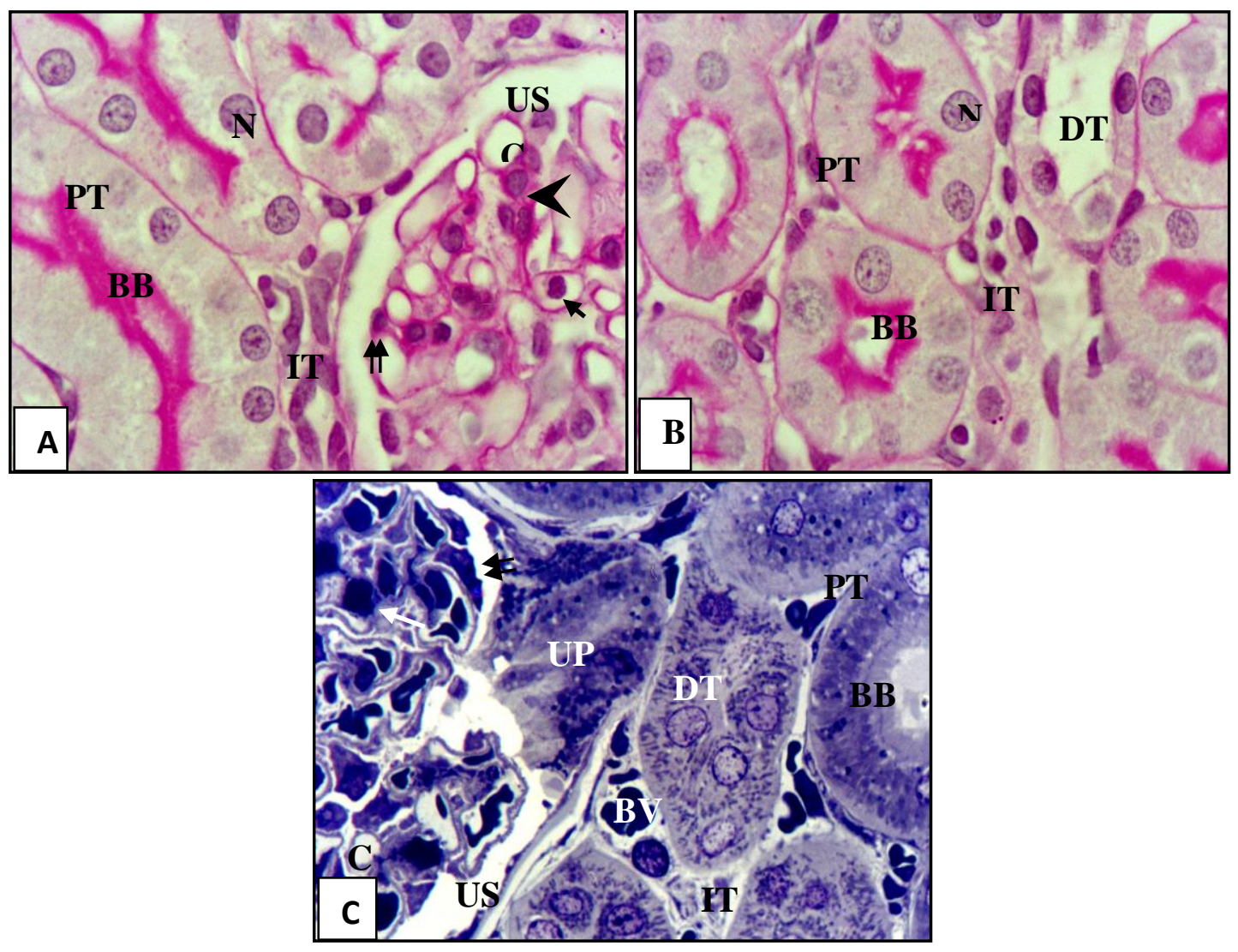

Plate 2: Light photograph for transverse section of Date-group kidney showing: 
A-Normal renal corpuscle have distinct capillary lumen (C), urinary space (US), endothelial cells (arrow), mesangial cells (head arrow), podocyte cells (double arrow). Proximal tubules (PT) with clear brush border (BB) and round central nuclei (N). Interstitial tissue (IT) (P.A.S.). B-Proximal tubules (PT) have high cells with contact brush border (BB), round nuclei (N) and stare lumen. Distal tubule (DT) with low height cells and large lumen (P.A.S.). C-Part of glomerulus contains capillary lumen (C), mesangial cells (arrow), podocyte cells (double arrow), distinct urinary space (US), and urinary pole (UP). Normal brush border (BB) in proximal tubule (PT), distal tubule (DT) and blood vessel (BV) in interstitial tissue (IT) (T.B.; X1000).

When the kidney specimens obtained from the Date-group and examined with light microscope, normal histological structure of the proximal tubules was observed. As shown in (Plate 2A) is the tubule with normal brush border and central round nuclei. The brush border was contact and the lumen took the star-shape (Plate 2B) and no congestion noticed in interstitial tissue (Plate 2C).

Plate (3):

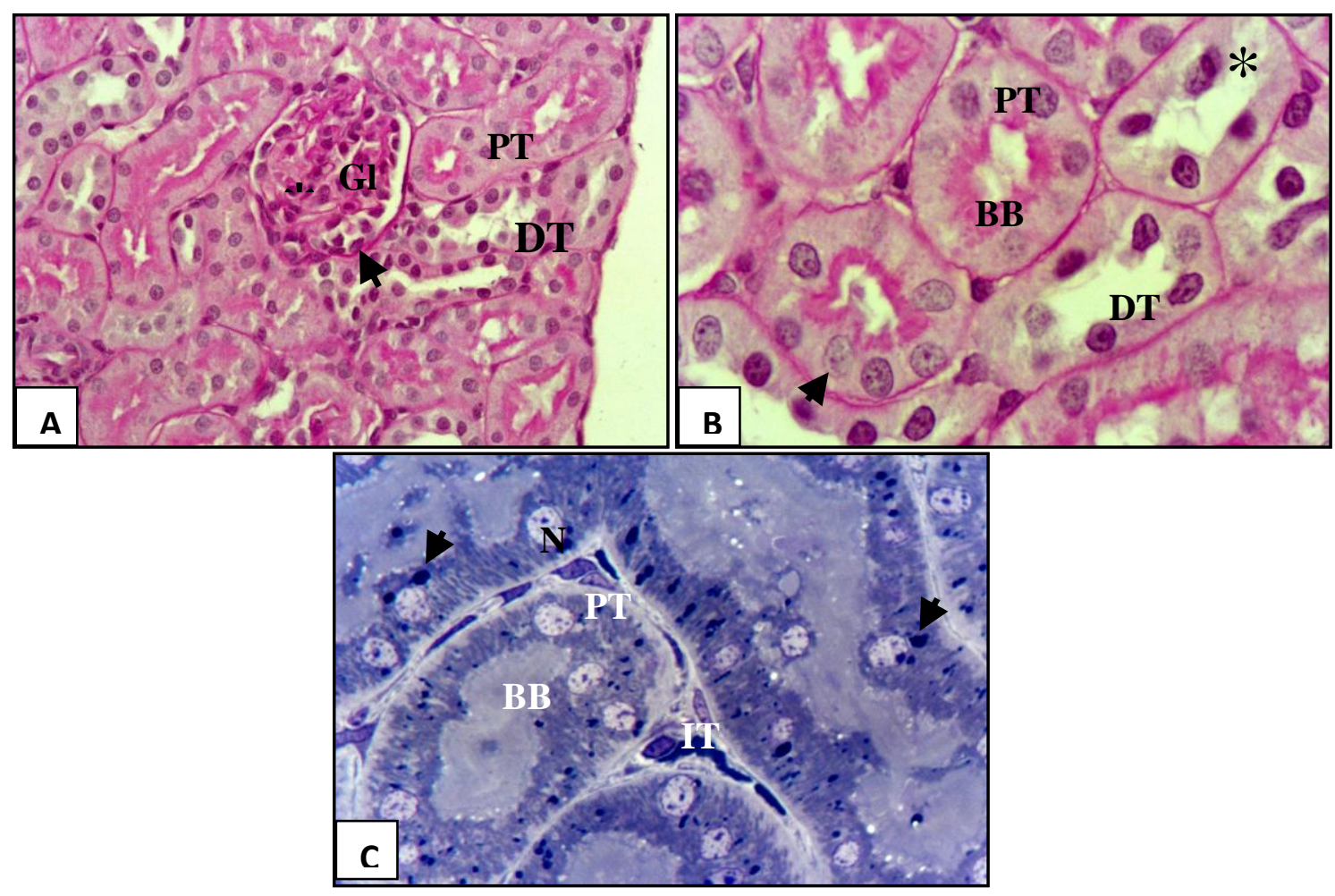

Plate 3: Light photograph for transverse section of Date + OTA-group kidney showing:

A-Glomerulus (Gl) with proliferated podocytes (arrows), few expanded mesangial matrix (asterisk), surrounded by proximal tubules (PT) with normal brush border. Note distal tubules (DT). (PAS, × 400) B-Nearly normal proximal tubules $(\mathrm{PT})$ with clear brush border $(\mathrm{BB})$, many eccentric nuclei and few karyolitic nuclei (arrows). Distal tubules (DT) with 
degenerated cytoplasm and extruded nucleus (asterisks). (PAS, $\times 1000)$ C. Proximal tubules with normal round nuclei $(\mathrm{N})$ and organized brush border $(\mathrm{BB})$, few lysosome-like vesicles (arrows). Note interstitial tissue (IT). (TB, $\times 1000)$

In the present study, a significant decrease in the severity of histopathological and morphometric changes induced by OTA was observed in animals treated with OTA+ Date when compared with the OTA- group. From plate (3) it was clear that in some area few proximal tubule still affected which have lytic nucleus but its brush border appeared normal (Plate 3A) but in most area nearly normal proximal tubules with eccentric nuclei (Plate 3B), normal abundant brush border, distinct nuclei and lysosome-like vesicles (Plate 3C) were detected.

Plate (4):
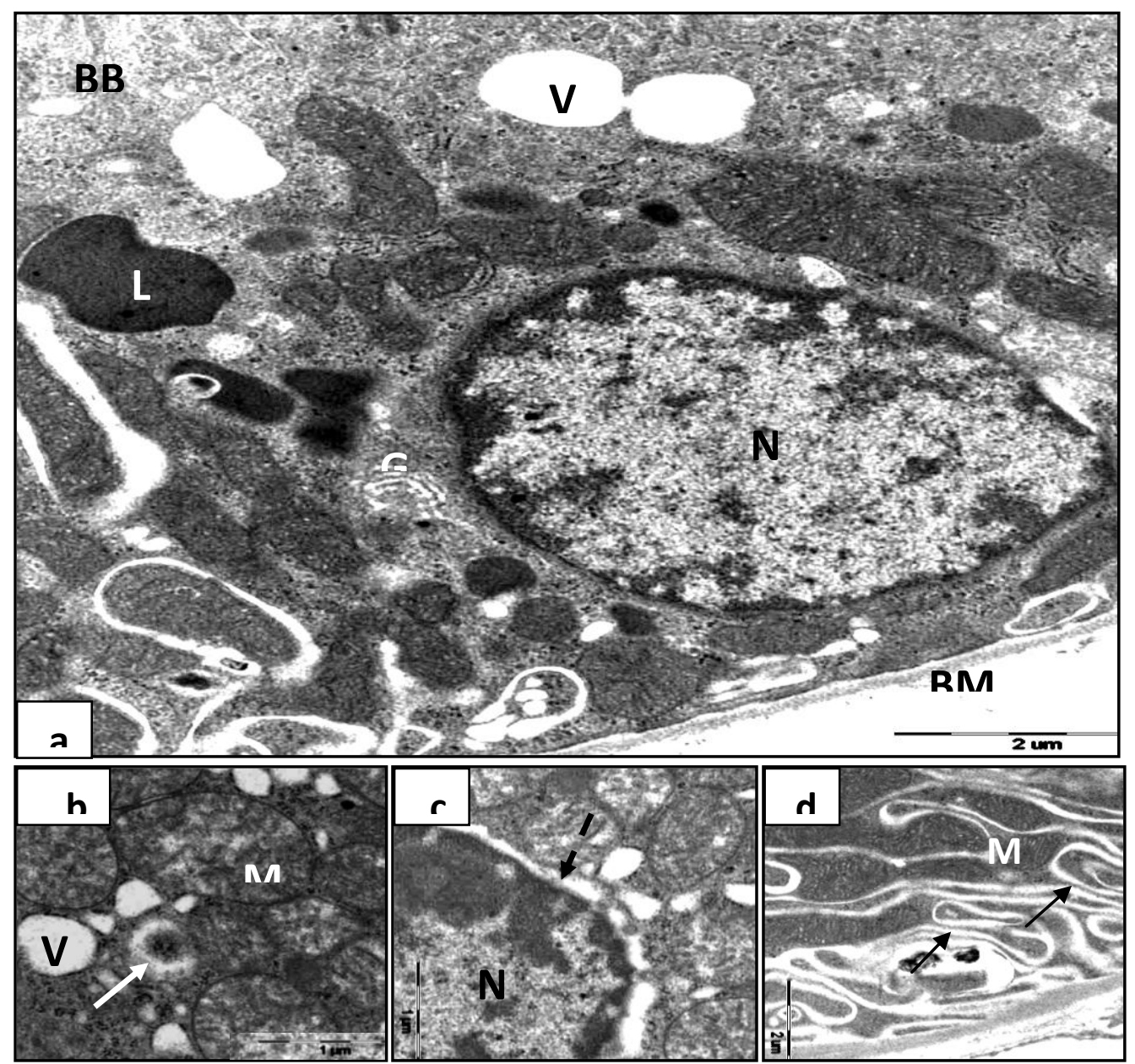

Plate (4): Transmission electron micrograph of ultrathin OTA Kidney sections showing: a) proximal convoluted tubule cell with focal loss brush border (BB), numerous apical vesicles $(\mathrm{V})$, numerous lysosomes $(\mathrm{L})$, deformed Golgi zone $(\mathrm{G})$, nucleus $(\mathrm{N})$ with marginal

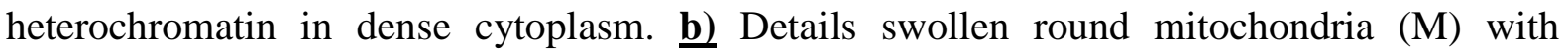
indistinct cristae, vesicles (V) and secondary lysosome (L). 드 Detail apoptotic cell with 
nucleus have invaginated nuclear envelope and heterochromatin condensation. $\underline{\mathbf{d}) \text { detail }}$ double short basal infolding membrane (arrows) with bizarre mitochondria (M).

The electron microscopic observations of the OTA- group (Plate 4) showed tubular changes such as shortening and loss of basal infolding, rounded mitochondria with disordered cristae, focal loss of brush border, and invagination of the nuclear envelope, the increased number of lysosomes, deformed Golgi zone and nucleus heterochromatin condensation in dense cytoplasm (Plate 4a), the mitochondrial swelling with lysis of cristae and presence of secondary lysosome (Plate 4b), apoptotic cell nucleus have peripheral heterochromatin condensation and invagination of nuclear envelope (Plate 4c). Also, and double short basal infolding membrane with bizarre mitochondria were noticed (Plate 4d).

Ultra-examination of Date- group reveled normal cyto-structure of the proximal tubules where they appeared with contact brush border, small lysosome, active nucleus, large elongated organized mitochondria in-between extended basal enfolding (Plate A5) and well developed pinocytotic vesicles under the arranged microvilli (Plate 5B). Also, the nucleus with peripheral heterochromatin surrounded with homogenated cytoplasm contained free

Plate (5):
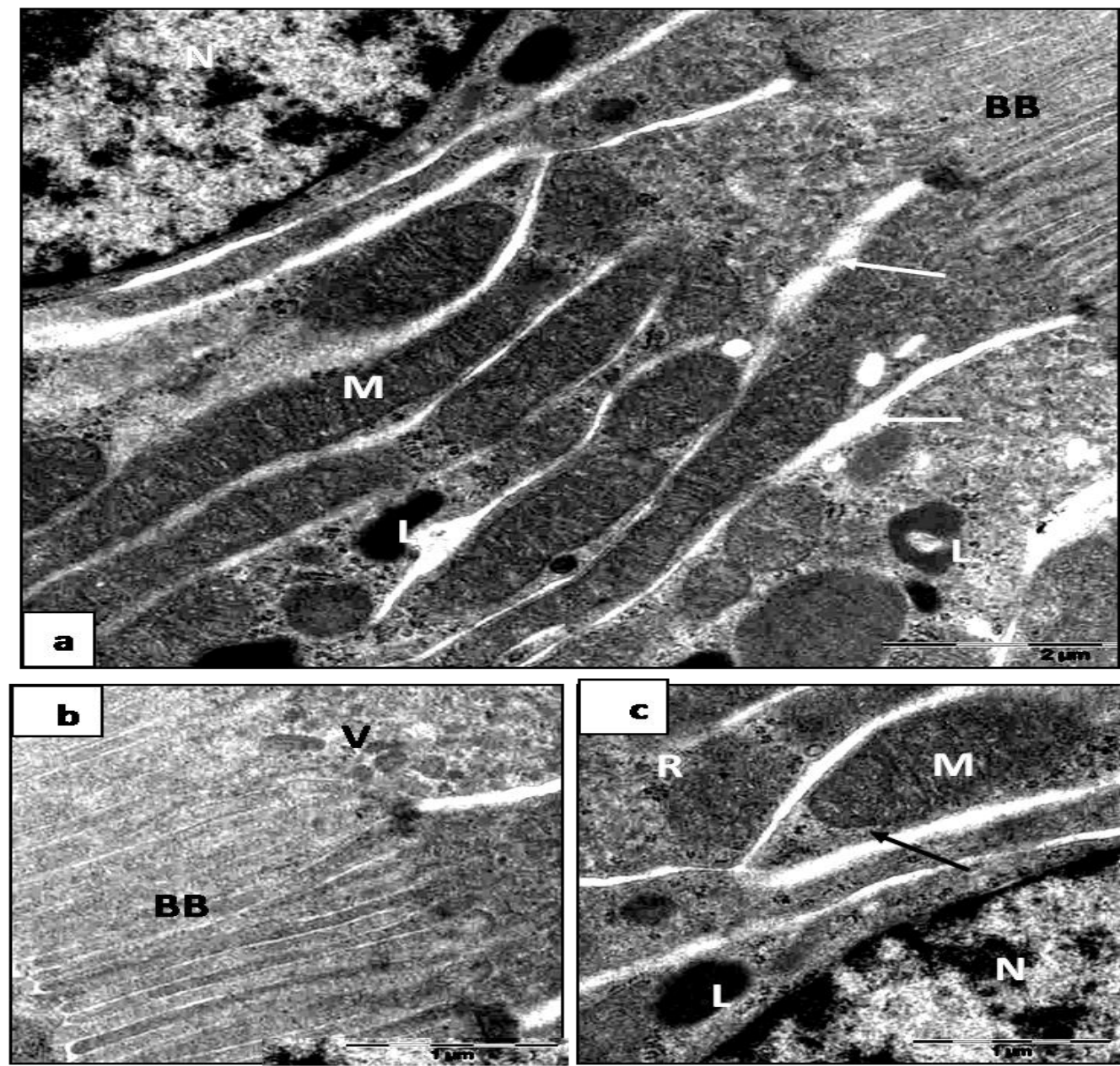
ribosome, lysosome, homogenous mitochondria with normal cristae and at the base double membrane basal infolding were seen (Plate 5C).

Plate (5): Transmission electron micrograph of ultrathin of Ajwa Date- Kidney sections showing: a) part of proximal tubule cell reveals normal brush border (BB), small lysosome $(\mathrm{L})$, nucleus $(\mathrm{N})$ and large elongated mitochondria $(\mathrm{M})$ in-between extended basal infolding (arrows). $\underline{\mathbf{b})}$ details intact brush border (BB) and well developed pinocytotic vesicles (V) $\underline{\mathbf{c}}$ details part of nucleus (N) with peripheral heterochromatin, lysosome (L) ,homogenous mitochondria (M) with normal cristae, double membrane basal infolding (arrow), and free ribosome $(\mathrm{R})$.

Plate (6)
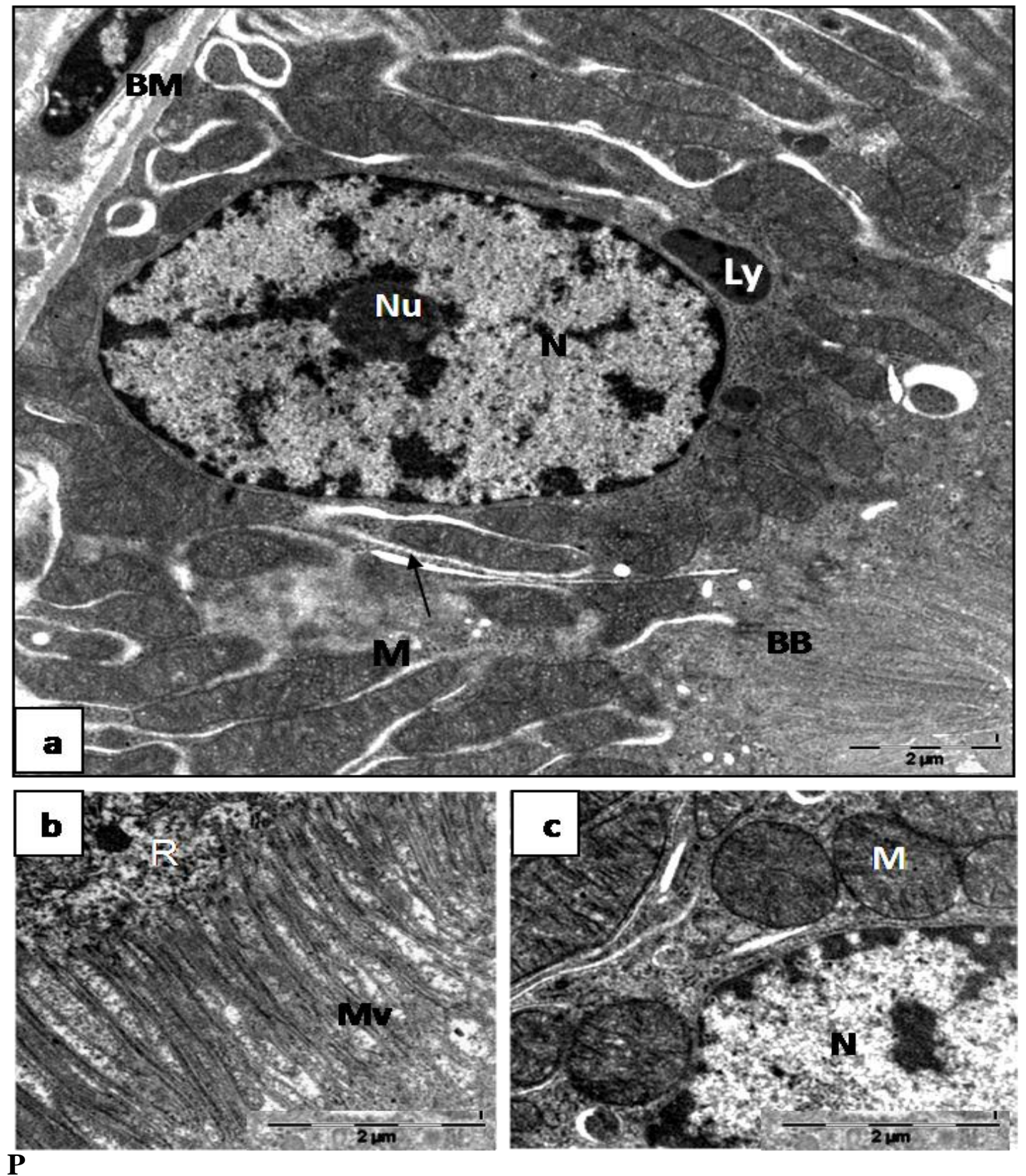
late (6): Transmission electron micrograph of ultrathin of Ajwa Dates +OTA kidney sections showing: a) proximal tubular cell with organized brush border (BB), euchromatic nucleus $(\mathrm{N})$ with nucleolus $(\mathrm{Nu})$, healthy mitochondria $(\mathrm{M})$, basal infoldings (black-arrow) and basement membrane (BM). b) Unpacked microvilli and free ribosome (R). c) Detail nucleus $(\mathrm{N})$ surrounded by intact nuclear envelope, mitochondria $(\mathrm{M})$ with distinct membrane (M).

The consumption of Date fruit extract restored the tubule damage induced by OTA, as revealed by improvement of ultrastructure changes (Plate 6) where tubular cell with organized brush border, euchromatic nucleus with nucleolus surrounded by intact nuclear envelope and mitochondria with distinct membrane (Plate 6a) were observed. The unpacked microvilli and free ribosome illustrated at plate $(6 \mathrm{~b})$, the nucleus surrounded by intact nuclear envelope and mitochondria with distinct membrane were illustrated in plate (6c).

\section{Discussion}

The study of toxic effects of OTA under low dose exposure regimen was extremely important in order to have more data for human risk assessment [21]. Regarding general toxicity parameters, we observed insignificant reduction in both expected body and kidney weight increase in the low dose OTA- group as recorded before [21] and this led to low relative weight as agree with [22]. In the other hand, body and kidney weight had a significant decrease in Ajwa date + OTA -group and a significant increase in Ajwa Date- group in compare with control-group, this might be due to high carbohydrate amount of Date [12].

With respect to biochemical parameters, blood urea and creatinine content were increased in OTA- group but these differences were not statistically significant as recorded before $[20,22]$.The increase in these substances pointed to pathological alterations in the kidney [23], especially degeneration of proximal tubules [24]. In the Ajwa Date- group non significant decrease in creatinine level with non significant increase in urea level were recorded in compare with control -group and this increase in urea level might be due to high protein content in Date which led to increase urea level in blood [25].

In animal models, the S3 segment of proximal tubule appears to be major site of renal injury [26] and this was illustrated in this study where non significant increase in the area of both proximal tubules, proximal tubules lumen and proximal tubules nuclei were detected in OTA- group. In the other hand, non significant decrease was noticed in the area of both proximal tubules, proximal tubules lumen in OTA+ Date- group, as agreed with [27] study. OTA was a widespread mycotoxin which when intaken via diet passed into the blood and accumulated in organs, such as kidneys; potentially imposing serious damage to these organs [28] and this might explain the nephrotoxic actions of OTA which led to necrosis of renal tubular cells.

The present results were compatible with [20], as OTA exhibited cloudy swelling of proximal tubules in addition to tubular eosinohilic intraluminal proteinaceous casts and congestion as indicated before [29]. In addition to these findings karyomegalic nuclei were observed in tubular epithelial cells, where karyomegaly of tubular epithelial cells as an early 
stage marker of the nepherotoxicity by OTA $[2,23]$. Also, marked interstitial fibrosis was detected as indicated before [30].

When the kidney specimens from the Date- group examined with light microscope, normal histological structure of the proximal tubules was indicated in agree with [31]. In the present study, a significant decrease in the severity of histopathological and morphometric changes induced by OTA was observed in animals treated with OTA+ Date when compared with the OTA- group where Date served as good source of natural antioxidants and could potentially be considered as a functional food ingredient [10] and previously it showed that Date extracts possess significant antioxidant action in vitro [11].

The electron microscopic observations of the OTA- group were in agreement with those in the literatures: tubular changes such as shortening and loss of basal infolding, rounded mitochondria with disordered cristae, focal loss of brush border, and invagination of the nuclear envelope [27]. The increased number of lysosomes, a result of the attempt to digest toxic substances, was considered a general manifestation of injury. The sequestration of damaged organelles in lysosomes was a mechanism of cellular repair and follows all types of sublethal injury [34]. The mitochondrial swelling and lysis of cristae might reflect the disturbances in oxy-reduction processes taking place in the organelle[33] as, the mitochondria were the source of reactive oxygen species (ROS) and a target of excessive ROS generation [34].Excess ROS increased the mitochondrial membrane permeability and damaged the respiratory chain resulting in increased ROS production [35]. The disruption in the mitochondrial membranes caused the release of cytochrome $\mathrm{c}$ from mitochondria, which initiated events leading to apoptosis as; ROS were thought to play a role in TNFR and Fas receptor- mediated apoptosis [36]. Also, changes in the nucleus, such as heterochromatin condensation and margination, which was found in the present study, indicates that this organelle was affected in a major way from OTA exposure suggested progressive inactivation of the nuclear component, probably due to inhibition of DNA repair and DNA methylation [37]. The reaction of OTA with proximal tubule cell basolateral membrane might lead to loss of basolateral invagination like isplatin $\mathrm{C}$ action [27].

Ultra-examination of Date-group reveled normal cyto-structure of the proximal tubules as indicated before [32]. In the other hand, the consumption of Date fruit extract restored the tubule damage induced by OTA as revealed by improvement of ultrastructure changes where in vivo Date palm fruit may be useful for the prevention of oxidative stress [16] as the date flesh demonstrated a strong free radical scavenging activity [38]. The antioxidative properties of Date in vitro [39] might exert a protective effect on OTA- induced damages.

\section{Conclusion:}

Chronic administration of low dose of OTA caused morphological and functional changes in proximal tubules and administration of Date extract would be effective in protecting against OTA-induced tubule's tissue damage. It was possible that the toxic effect of OTA was 
somehow minimized by a compensatory mechanism involving Date via the induction of antioxidant enzyme activity following administration of Date.

\section{Recommendations:}

These results highlight the need to reduce OTA exposure where its accumulative effect causes extensive damage to the proximal tubules. Additionally, pay particular attention to our diet to be rich in antioxidants such as Date where the chronic administration of Date may be of therapeutic benefit on OTA nephrotoxicity.

Abbreviations: Ochratoxin A (OTA), Haematoxylin and Eosin (H\& E.), Periodic AcidSchiff (PAS), Masson’s Trichrome (M.T.).

\section{Competing interests:}

The authors declare that they have no competing interests.

\section{Authors' Contributions:}

Awatef Ali, PhD is the principle investigator for this study performed all of the lab work for the study, providing oversight and contributed fundamental conceptualization for the research, writing a grant proposal and manuscript.

Susan. Abdu, PhD is provided statistical analysis and assisted in writing the manuscript. suzanabdu@yahoo.com

\section{Acknowledgements and Funding:}

This study was supported as Project (196-17) by Adula-Aziz City for Science and Technology.

\section{References:}

1. Tapia O, Seawright A. Experimental ochratoxicosis A in pigs.1984; Aust Vet J 61: 219222.

2. Adler M, Muller K, Rached E, Dekant W, Mally A. Modulation of Key Regulators of Mitosis Linked to Chromosomal Instability is an Early Event in Ochratoxin A Carcinogenicity, Carcinogenesis 2009; 30 (4): 711-719.

3. Mantle P, Kulinskaya E. Lifetime, low-dose ochratoxin A dietary study on renal carcinogenesis in male Fischer rats. Food Addit. Contam. Part A Chem. Anal. Control Expo. Risk Assess, 201027 (11): 1566-1573.

4. Okutan H, Aydin G, Ozcelik N. Protective Role of Melatonin in Ochratoxin A Toxicity in Rat Heart and Lung, Journal Appl. Toxicology 2004; 24 (6): 505- 521.

5. Malekinejad H, Mirzakhani N, Razi M, Cheraghi H. Alizadeh A. Dardmeh F. Protective effects of melatonin and Glycyrrhiza glabra extract on ochratoxin A-induced damages on testes in mature rats. Hum Exp Toxicol. 2010; Apr 22.

6. Aukema H, Housini I, Rawling J. Dietary soy protein effects on inherited polycystic kidney disease are influenced by gender and protein level. J Am Soc Nephrol.1999; 10:300-308. 
7. Bayman P, Baker J. Ochratoxins: A Global Perspective. Mycopathologia. 2006.; 162 (3): 215- 223.

8. Shahidi F, Naczk M. Phenolics in Food and Nutraceuticals. CRC Press: Boca Raton, FL. 2004.

9. Vayalil P. Antioxidant and Antimutagenic Properties of Aqueous Extract of Date Fruit (Phoenix Dactylifera L. Arecaceae). Journal Agric. Food Chemistry. 2002; 30; 50 (3): 610- 617.

10. Al-Shahib W, Marshall R. The Fruit of the Date Palm: its Possible Use as the Best Food for the Future? Int. Food Science Nutr. 2003; 54 (4): 247- 259.

11. Saafi B, Louedi M, Elfeki A, Zakhama A, Najjar F, Hammami M, Achour L. Protective effects of date palm fruit extract (Phoenix dactylifera L.) on dimethoate induced-oxidative stress in rat liver. Exp Toxicol Pathol. 2010; Epub ahead of print

12. Hasan S, Amom H, Nor I, Mokhtarrudin N, Esa M, Azlan A.Nutritional composition and in vitro evaluation of the antioxidant properties of various dates extracts (Phoenix dactylifera L) from libya.Asian J.Clin.Nutr.2:208-214.

13. Rock W,Rosenblat M,Borochov-Neori H,Volkova N,Judeinstein S,Elias M, Aviram M.Effects of date (Phoenix dactylifera L.,Medjool or Hallawi Variety ) consumption by healthy subjects on serum glucose and lipid levels and on serum oxidative status :A pilot study.J.Agric.Food Chem.2009;57:8010-8017.

14. Miller J, Dunn V, Hashim B. The Glycaemic Index of Dates and Date/yoghurt Mixed Meals, Are Dates "the Candy that Grows on Trees"? European Journal of Clinical Nutrition. 2003. 57: 427- 430.

15. Chang C, Lau E, Lin B. Estradiol-17B suppresses testicular development and stimulates sex reversal in protandrous black porgy, Acanthopagrus schlegeli.Fish Physiol .Biochem. 1995; 14:481-488.

16. Bancroft J, Gamble M. Theory and Practice of Histological Techniques. $5^{\text {th }}$ edition, Churchill Livingstone. 2002.

17. Mould R. Introductory Medical Statistics. $2^{\text {nd }}$ edition, Adam Hilget, Briotl and Philadelphia. 1989.

18. Alvarez L, Gil G, Ezpeleta O, Garcia-Jalon J, Lopez de Cerain A. Immunotoxic Effects of Ochratoxin A in Westar Rats after Oral Administration. Food Chemistry Toxicology 2004; 42 (5): 825- 834.

19. Maaroufi K, Zakhama A, Baudrimont I, Achour A, Abid S, Ellouz F, Dhouib S, Creppy E. Bacha H. Karyomegaly of Tubular Cells as Early Stage Marker of the Nephrotoxicity Induced by Ochratoxin A in Rats. Human Exp. Toxicology 1999; 18 (6): 410- 415.

20. Stoev D, Vitanov S, Anguelov G, Petkova-Bocharova T, Creppy E. E. Experimental Mycotoxic Nephropathy in Pigs Provoked by a Diet Containing Ochratoxin A and Penicillin Acid. Veterinary Research Communications. 2001; 25 (3): 205 - 223.

21. Turner N, Savill J, Stewart L, Cumming A. Kidney and Genitourinary Disease. In Davidson's principles and practice of medicine by Christopher Haslett; Edwin R. 
Chilvers; Nicholas A. Boon; and Nicki R. College, $19^{\text {th }}$ edition, Churchill Livingstone, Edinburgh. 2002.

22. Al-Wahypy A.Medical Analysis and its pathological indications $2^{\text {nd }}$ edition, Electronic Printer, Al-Riad 2000

23. Sueishi K, Mishima K, Makino K, et al. Protection by a radical scavenger edaravone against cisplatin-induced nepherotoxicity in rats. Eur. J. Pharmacol. 2002; 451:203-208.

24. Tarladacalisir T, Kanter M , Uygun M. Protective Effects of Vitamin C on Cisplatininduced Renal Damage a Light and Electron Microscopic Study. Renal Failure 2008; 30: 1- 8 .

25. Petzinger E, Ziegler K. Ochratoxin A from a Toxicological Perspective. Journal Vet. Pharmacology Ther. 2000; 23: 91- 98.

26. Munro C, Scott M, Moodie A, Willes F. Ochratoxin A occurrence and toxicity. J Am Vet Med Assoc. 1973; 63:1269-1273.

27. El-Arab A, Girgis S, Hegazy E, Abd El-Khalek A. Effect of dietary honey on intestinal micro flora and toxicity of mycotoxins in mice. BMC Complement Altern. Med.2006; 6: 6-6.

28. Arbillaga L, Vettorazzi A, Gil G, Van Delft H, Garcia-Jalon J, Lopez de Cerain A. Gene Expression Changes Induced by Ochratoxin A in Renal and Hepatic Tissues of Male F344 Rat After Oral Repeated Administration. Toxicology App. Pharmacology 2008; 15; 230 (2): 197- 207.

29. Milicevic D, Juric V, Stefanovic S, Jovanovic M, Jankovic S. Survey of Slaughtered Pigs for Occurrence of Ochratoxin A and Porcine Nephropathy in Serbia. Int. Journal Mol. Science. 2008, 9: 2169- 2183.

30. Junqueira L, Carneiro J. Basic Histology, Text and Atlas. $9^{\text {th }}$ edition, McGraw-Hill Companies. USA. 2003. Datta, K., Sinha, S. and Chattopadhyay, P. (2000) Reactive oxygen species in health and disease. Nat. Med. I. India, Vol. 13: 304-310.

31. Cheville N. Ultrastructural Pathology: An Introduction to Interpretion1. st Edn. Ames, Iowa: Iowa state University Press. 1994; 67 - 68.

32. Thevenod F. Nephrotoxicity and the proximal tubule. Insights from cadmium. Nephron Physiol. 2003; 93:87-93.

33. Pulido A, Parrish G. Chen F, Vallyathan V, Castranova V, Shi X. Cell apoptosis induced by carcinogenic metals.Mol.Cell Biochem. 2001; 222:183-188.

34. Anane R, Creppy E. Lipid peroxidation as pathway of aluminium cytotoxicity in human skin fibroblast cultures: Prevention by superoxide dismutase plus catalase and vitamins $\mathrm{E}$ and C. Hum. Exptl. Toxicol.2001; 20:477-481.

35. Krammer, P. CD95 (APO-1/Fas)-mediated apoptosis: Live and let die.Adv.Immunol. 1999; 71:163-210.

36. Waisberg M, Joseph B, Hale O, Beyersmann D. Molecular and cellular mechanisms of cadmium carcinogenesis .Toxicology 2003;192:95-117. 
37. Chaira N,Ferchichi A, Mrabet A, Sghairoun M.Chemical composition of flesh and pit of date palm fruit and radical scavenging activity of their extracts. Pak.J.Biol. Sci. 2007; 10:22202-2207.

38. Rock W, Rosenblat M, Borochov-Neori H, Volkova N, Judeinstein S, Elias M, Aviram M. Effects of date (Phoenix dactylifera L., Medjool or Hallawi Variety) consumption by healthy subjects on serum glucose and lipid levels and on serum oxidative status. J. Agric. Food Chem. 2009; 9; 57(17): 8010-8017.

39. Kumar M, Dwivedi A, Sharma N, Singh D, Patil R. Ochratoxin A and citrinin nephrotoxicity in New Zealand white rabbits: An ultrastructural assessment. Mycopathologia 2007; 163: 21-30. 